\title{
Can Temperature and Water Availability Contribute to the Maintenance of Latitudinal Diversity by Increasing the Rate of Biotic Interactions?
}

\author{
Jordi Moya-Laraño ${ }^{*}, 1,2$ \\ ${ }^{I}$ Department of Evolutionary and Functional Ecology, Estación Experimental de Zonas Áridas. CSIC. General Segura, \\ 1. 04001-Almería, Almería, Spain; ${ }^{2}$ Cantabrian Institute of Biodiversity, Biología de Organismos y Sistemas, \\ Universidad de Oviedo-Principado de Asturias-CSIC, 33006-Oviedo, Asturias, Spain
}

\begin{abstract}
Environmental gradients (such as average annual temperature increasing towards the tropics) are numerous across the globe. Here I propose a theory, comprised of progressive hypotheses, which links temperature and water availability to the maintenance of high genetic and phenotypic diversity in the tropics through enhanced biotic interactions. In terrestrial ecosystems higher temperatures and water availability, by allowing higher rates of mobility, growth and reproduction of organisms, should lead to higher rates of encounter among individuals in communities. Due to this, interactions in wet and warm environments, such as tropical rainforests, should be both more frequent and more diverse regardless of the number of species present. This diversity of interactions is illustrated at the genotype level, stressing whether genotypes interact positively or negatively with other genotypes, and considering species, as well as individuals, as genotypes. Such biotic interactions in environments can generate strong genotype-environment interactions that can promote the maintenance of high levels of (functional) genetic and phenotypic diversity. This can subsequently facilitate coexistence and speciation processes. The paper finishes by proposing future research to test the hypotheses and hence the overall theory presented here.
\end{abstract}

Keywords: Encounter rate, maintenance of genetic variation, genotype-environment interaction in fitness, phenotypic flexibility, water availability and temperature, diversity gradients.

\section{INTRODUCTION}

\section{A Brief Review of Hypotheses that Explain Latitudinal Diversity Gradients}

The distribution of diversity on Earth is not random, but displays several gradients (Ricklefs and Schluter 1993; Rosenzweig 1995; Hillebrand 2004; Mittelbach et al. 2007). These global patterns of species richness have interested researchers for over 100 years (Wallace 1878; Dobzhansky 1950; Fischer 1960). Several hypotheses try to explain the latitudinal diversity gradient (reviewed in Willig et al. 2003; Mittelbach et al. 2007). The "time and area hypothesis" (Wallace 1878) states that because the tropics have occupied a large area for a long period of time, more species have accumulated there. However, evidence suggests that despite tropical habitats existing for longer periods of time relative to temperate ones this, by itself, does not explain the latitudinal diversity gradient (Mittelbach et al. 2007). Recently, Arita \& Vázquez-Domínguez (2008) have proposed a dynamic null model against which current gradients can be contrasted. However, ecological and evolutionary explanations are still needed to explain latitudinal diversity gradients.

The "effective evolutionary time hypothesis" (Fischer 1960; Rohde 1992) states that because in ectotherms higher

\footnotetext{
*Address correspondence to this author at the Cantabrian Institute of Biodiversity, Biología de Organismos y Sistemas, Universidad de OviedoPrincipado de Asturias-CSIC, 33006-Oviedo, Asturias, Spain; Tel: +34950281045; Fax: +34950277100; E-mail: jordi@eeza.csic.es

Handling Editor: Jennifer Hill
}

temperatures lead to shorter generation times and higher mutation rates (from higher metabolic rates and subsequent free radical release), this will, in turn, generate faster divergence among populations. This divergence will be facilitated by the higher metabolic rates induced by higher temperatures, which will speed up selection due to accelerated physiological processes (Rohde 1992). Indeed, there is a widely documented positive relationship between available energy and species richness (Mittelbach et al. 2001; Evans and Gaston 2005). Allen et al. (2002) framed this hypothesis in the context of the metabolic theory of ecology (MTE), explaining diversity gradients by linking the evolutionary and ecological processes to plant and animal metabolic rates. However, a recent attempt to test this hypothesis failed to support the model (Hawkins et al. 2007). Although the regression models of Hawkins et al. (2007) did not support the quantitative predictions of the MTE, they still found significant positive linear relationships between species richness and temperature in 32 out of 46 data sets, suggesting that temperature may explain the latitudinal diversity gradient. Other shortcomings of the effective evolutionary time hypothesis have also been highlighted (reviewed in Evans \& Gaston 2005; Mittelbach et al. 2007). Hawkins et al. (2003) further showed that understanding water-energy relationships was crucial to understand the global patterns of diversity. In addition, Latimer (2007) showed how, at high temperature, water availability was a better predictor of species richness. Thus, additional explanations seem to be necessary for a better understanding of the patterns of diversity. These new explanations should identify the role of historical factors in current distributions as well as the interplay between regional and local ecological 
patterns in the current distribution of biota (Ricklefs and Schluter 1993; Ricklefs 2004).

An alternative classic view that provides an explanation of the latitudinal diversity gradient is the "biotic interactions hypothesis" (Dobhanzky 1950; Fischer 1960; Currie et al. 2004; Guernier et al. 2004; Mittelbach et al. 2007). According to this hypothesis, the relatively constant and mild climate conditions of the tropics allow biotic interactions to play an important role in diversification. The harsh environment of higher latitudes, in contrast, does not facilitate biotic interactions and diversification occurs at a lower rate. According to Dobhansky (1950), due to extreme climate conditions selection would be random and disastrous in higher latitudes and elimination would "acquire a differential character" from biotic interactions at lower latitudes. Schemske (2002) argues that diversity in the tropics may be originated from geographical differences in the pattern and magnitude of species interactions and that newly isolated tropical populations are forced into new coevolutionary pathways and hence species evolve along new trajectories. However, as Schemske himself recognizes, one caveat of the latter interpretation is that more diversity is necessary in the first instance in order to generate further diversity (Schemske 2002). In addition, as currently formulated, the biotic interactions hypothesis does not successfully explain how we move from constant climate conditions to higher species richness. A possible link could be established if biotic interactions could contribute to the maintenance of higher genetic and phenotypic diversity within populations, which could consequently facilitate speciation and coexistence.

\section{An Outline of the Proposed Theory}

Abiotic factors, such as temperature and water availability, show strong gradients across the globe. In terrestrial ecosystems, temperature and water availability decrease with latitude, and temperature decreases with altitude while precipitation can reach its highest at intermediate elevations (Walter 1975). Several discrete hypotheses have been put forward to link temperature and water gradients with biological diversity (e.g. Rohde 1992; Allen et al. 2002; Hawkins et al. 2003; Hawkins et al. 2007). Attempts to establish this link have been made, for instance, with respect to latitudinal gradients of species richness (species richness increasing towards the Equator) (reviewed in Willig et al. 2003; Mittelbach et al. 2007). However, to the author's knowledge no attempt has been made to establish a relationship between water availability and temperature, the frequency and diversity of biotic interactions, and the maintenance of (functional) genetic and phenotypic diversity at the global level. The maintenance of genetic and phenotypic diversity is important both from an evolutionary as well as from an ecological point of view. First, genetic diversity may enhance the rate of ecological speciation, as a lack of genetic diversity may constrain population fitness (Schluter 2000). Furthermore, given the growing evidence that developmental plasticity may also contribute to the generation of novelty and speciation (West-Eberhard 2003), the overall amount of phenotypic diversity (both from constitutive genes as well as from plasticity) may be an important determinant of diversification. Second, from an ecological point of view, species coexistence may largely depend on the available genetic diversity within interacting populations (Vellend and Heber 2005, Vellend 2006, Hughes et al. 2008), as well as on the degree of phenotypic plasticity (Peacor et al. 2006). Thus, understanding how temperature and humidity can affect biotic interactions and the maintenance of genetic diversity has the potential to alter our current view on how global warming and climate change could be linked to the maintenance of biodiversity on Earth.

In this paper, I use existing literature to develop a theory, comprised of logical and progressive hypotheses, which links temperature and water availability with the maintenance of genetic and phenotypic diversity through increasing the rate of biotic interactions. Published literature is used to build up a comprehensive framework of testable hypotheses and to develop from them an integrated meta-theory. To the author's knowledge the hypotheses have not been brought together in such a clear and progressive manner previously. Throughout this paper, biotic interactions are defined as Genotype-Genotype interactions $(\mathrm{GxG})$, without regard to which species a genotype belongs to. Thus, for simplicity, both intra- and inter- specific interactions are considered similarly, even though it is acknowledged that they might differ substantially in mode, strength and direction.

Fig. (1) shows the causal links comprising the theory. The novelty of the argument is the realization that abiotic factors of global effect (e.g. water availability and temperature in terrestrial ecosystems) constrain the mobility, growth and reproduction of most organisms and, where these are less constrained (e.g. in tropical rainforests), the encounter rate among organisms (genotypes) is potentially higher, which leads to an increased frequency and diversity of biotic interactions. This may enhance diversity in a number of ways (Fig. 1), which leads to the series of hypotheses that are

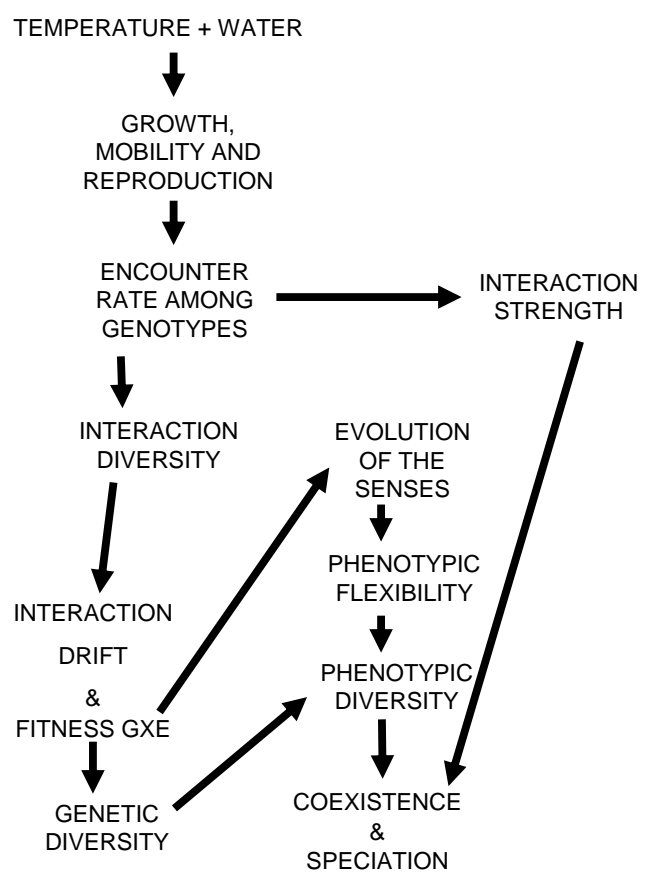

Fig. (1). Schematic representation of the theory that temperature and water availability can contribute to maintain genetic, phenotypic and species diversity by increasing the rate of biotic interactions (see text for details). 
delineated in this paper. In summary, higher temperature and water availability allow biotic interactions to be more frequent and diverse, which leads to fluctuating selection, Genotype-Environment interactions in fitness (fitness GxE, i.e. the same genotypes have different fitness in different environments) and diffuse coevolution (as opposite to tight pair-wise coevolution), which allow the maintenance of high genetic diversity. Also, strong fitness GxE should lead to the evolution of the senses and the evolution of phenotypic plasticity in labile traits. Higher phenotypic diversity enhances coexistence, and thus the maintenance of more species in communities, as well as ecological speciation. Furthermore, more encounters can lead to stronger interactions (as recognized in the tropics - e.g. Schemske 2002; Mittelbach et al. 2007), which will facilitate coexistence and speciation through tight pair-wise coevolutionary pathways. The net effect of all these processes should be to produce higher genetic and species diversity in warm and wet environments, such as tropical rainforests.

In aquatic environments, temperature alone could have a similar effect to water and temperature in terrestrial environments. A recent study involving the Major Histocompatibility Complex (MHC) in Atlantic salmon (Dionne et al. 2007) supports this view. These authors showed that, after including pathogen richness as a covariate in a linear model, there was an increase in allelic MHC richness with increasing temperature and with decreasing latitude. As predicted by the present theory, the diversity of neutral alleles (i.e. in microsatellite loci) showed a slope not different from zero with either temperature or latitude, strongly suggesting that temperature drives balancing selection (i.e. selection favoring different alleles in different environments) from biotic interactions. This is possibly the best evidence to date that biotic interactions enhanced by temperature entail a fine-grained selection mosaic (see below) that contributes to maintain higher genetic diversity.

\section{THE THEORY IN DETAIL}

The theory that increased temperature and water availability lead to more diverse biotic interactions, which facilitate the maintenance of higher functional genetic diversity and plasticity in populations, could explain how climate links to higher diversity in tropical environments. An important virtue of the proposed theory is that differential diversification across latitudes can start with the same number of available species and genotypes at all latitudes. What follows is a detailed explanation of the hypotheses that comprise the core of the theory.

\section{Hypothesis 1: In Terrestrial Communities, the Encounter Rate Among Genotypes Depends on Temperature and on Water Availability}

Considering that endothermic vertebrates are just a small part of the total species pool on earth (e.g. Wheeler 1990), and are likely a small part of the total biomass of terrestrial ecosystems (e.g. Fittkau and Klinge 1973), we can conclude that most life on earth is ectothermic. In ectothermic organisms, an increase in metabolic rate induced from higher temperatures should lead to an increase in biological activity (such as mobility, growth and reproduction). Similarly, due to the risk of desiccation, a decrease in water availability should lead to a decrease in biological activity in most organisms, as is the case in desert animals and plants (Allee et al. 1949; Went 1949). Here I argue that an increase of biological activity induced by higher temperatures and water availability may lead to a higher encounter rate among genotypes, which will entail a higher frequency and diversity of biotic interactions. For instance, temperature enhances mobility in ectothermic animals (e.g. Allee et al. 1949; Bauwens et al. 1995) and, as a consequence, the encounter rate among potentially interacting individuals may also increase (e.g. bees and flowers - Herrera 1995; predator-prey ectothermic interactions - Kruse et al. 2008; agonistic interactions in male dragonflies - Baird and May 2003; encounter rate between males and females - Moya-Laraño et al. 2007). Also, in animals the probability of entering diapause increases with latitude (e.g. Schmidt et al. 2005) as well as in deserts (Allee et al. 1949). Growth and reproduction is both water- and temperature-dependent in animals (Keilin 1959), plants (Kozlowski and Pallardy 2002; Cunningham \& Read 2003) and fungi (Kope et al. 2008). All these effects should be reflected in the rate of biotic interactions. For instance, an increase in parasitic prevalence and/or load with decreasing latitude or with temperature (e.g. Merino et al. 2008; Salkeld et al. 2008) could be related to the enhancing effect of temperature on encounter rates, particularly when water is not a strong limiting factor for vector populations. Similarly, there is a higher prevalence of plant diseases in wet environments (Gilbert 2005).

The range of temperature and/or water availability within which biological activity is possible must also depend on local or regional (latitudinal, altitudinal) adaptation. This means that some species adapted to high latitudes or altitudes may have higher biological activity (metabolic rates) at lower temperatures (e.g. Alvárez et al. 2006; Cano and Nicieza 2006). However, despite such local/regional adaptation, there should still be variation remaining to predict a strong latitudinal gradient in activity due to differences in temperature and water availability.

Faster growth and reproduction also involves a higher rate of space occupancy, which will also lead to higher encounter rates among genotypes. As biomass increases, new surface area is available for biotic interactions. For instance, when a plant grows at a high rate under relatively high temperature and high water availability, it will encounter relatively more new genotypes to compete and/or positively interact with (both below and above ground) while simultaneously offering relatively more surface to be attacked by herbivores and rootivores. Faster reproduction also involves a higher rate of propagule production and dispersal, which will be available for interactions with other organisms. This also potentially increases the encounter rate among genotypes at the regional scale.

\section{Hypothesis 2: A higher Encounter Rate Among Genotypes Increases the Diversity of Interactions}

During its lifetime, an individual living in warmer and wetter environments will encounter other community individuals at a higher rate than an individual that lives in colder and/or drier environments. Thus, this individual experiences a more diverse biotic environment during its 


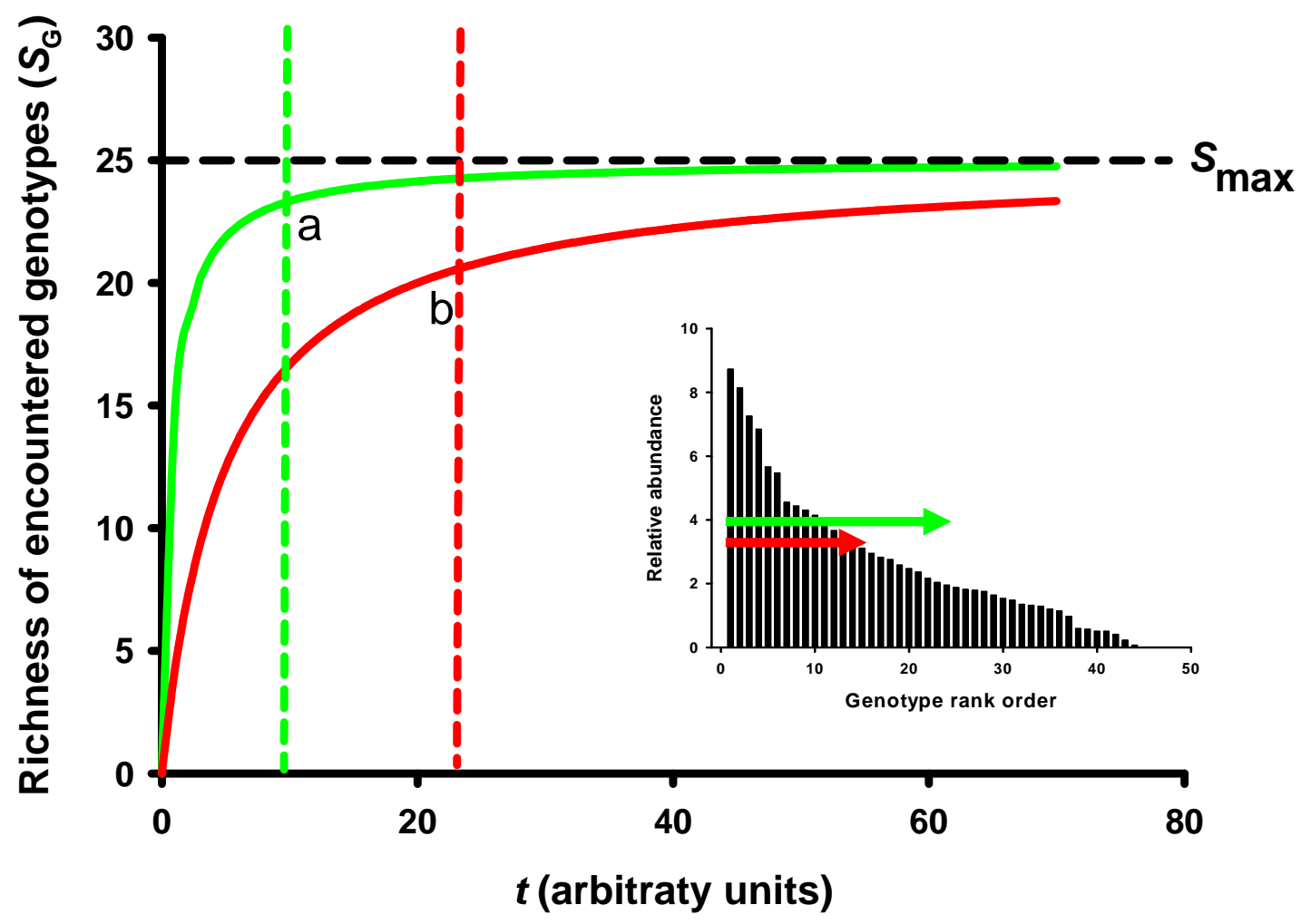

Fig. (2). Accumulation curve showing the number of different genotypes encountered by a random individual during its entire lifetime in two types of environments. Insert - Rank-abundance curves for the genotypes with which the individual can potentially interact. Green lines warm and wet environments (tropical areas); Red lines - cold and dry environments (temperate areas). The green and red dotted lines denote the maximum achievable lifespan for the species in tropical and temperate habitats respectively. The arrows within the rank-abundance curves indicate the number and type of genotypes encountered by a single individual. $S_{G}$ - cumulative number of different genotypes with which an individual interacts as it gets older (i.e. as time $t$ elapses). $S_{\max }$ - maximum number of different community genotypes with which an individual can interact.

lifetime. This process can be illustrated using a typical species accumulation curve, analogous to those used in diversity studies. Encounters with other organisms may be meaningful to the target individual in the sense that they may affect its fitness (i.e. interactions $+/+,-/-,+/-,-/+,+/ 0$; target individual on the left) or not at all (i.e. 0/0, 0/+, 0/-). From birth to death, an individual will encounter a portion of the genotypes composing the community. Just as if the individual was sampling genotypes as an insect collector, the accumulated number of new genotypes encountered will sharply increase over time, but will gradually decelerate (Fig. 2). The model is as follows:

$$
S_{G}=\frac{\beta_{i} t}{1+\frac{\beta_{i} t}{S_{\max }}}
$$

Where $S_{G}$ is the cumulative number of different genotypes with which an individual interacts as it gets older (i.e. as time $t$ elapses). $S_{\max }$ is the maximum number of different community genotypes with which an individual can interact. $\beta_{\mathrm{i}}$ denotes a coefficient that measures the rate of encounter with new genotypes in each habitat $i$. The central hypothesis is that for identical $S_{\max }$, warm and wet environments have higher $\beta$ 's (steeper accumulation curves) than temperate ones, leading to more diverse encounters $\left(S_{G}\right.$ 's). Thus, in a warm and wet environment, the decelerating part of the collector's curve will be less pronounced (Fig. 2), meaning that more new meaningful genotypes are encountered during the same lifespan in this environment when compared to a colder and/or drier environment. The encounter rate among genotypes will also depend on community size and the density, distribution and biomass of genotypes (i.e. how packed the community is). In general, since temperature affects ectothermic organisms more directly, the above effects should be less important in endothermic animals. However, the rate of encounter of endothermic animals with interacting ectothermic genotypes should also be affected.

An important assumption in the present hypothesis is that the shorter lifespans that some organisms experience at lower latitudes (Ziuganov 2000; Hautekèete et al. 2002; Rinde \& Sjotun 2005; Heibo et al. 2005; Blanck and Lamouroux 2007) will not cancel out the temperature and water enhancing effect on the number and diversity of biotic interactions that an organism experiences during its lifetime (compare $a$ and $b$ in Fig. 2). The generality of this assumption is supported by a number of facts: 1) There does not seem to be a general trend of shorter lifespans at lower latitudes depending on temperature. For instance, in aquatic ecosystems, Blanck and Lamouroux (2007) found that only 7 out of 13 fish species showed a latitudinal gradient in 
lifespan. 2) Although there is a general trend for organisms to increase their longevity at lower temperatures (Speakman 2005), there are examples of quadratic patterns in which, below a certain threshold temperature, lifespan increases with temperature. This is the case with the beetle Ahasverus advena, where increasing the temperature from $10^{\circ} \mathrm{C}$ to $15^{\circ} \mathrm{C}$ quadruples its lifespan (Jacob 1996). 3) Water availability in terrestrial environments seems to make animals live longer (e.g. Jacob 1996; Emana 2007; Tsunoda 2008) and thus, in tropical terrestrial environments, the joint effect of water and temperature on longevity can potentially cancel each other out. For instance, in the wasp Cotesia flavipes (Hymenoptera: Braconidae), average lifespan at $20^{\circ} \mathrm{C}$ and $45 \% \mathrm{RH}$ is 53 days, similar to that at $30^{\circ} \mathrm{C}$ and $85 \% \mathrm{RH}$, which is 60 days (Emana 2007). However, if lifespans are generally shorter in the tropics, this could lead to a faster individual turnover, as suggested by the high turnover rate shown by tropical trees relative to temperate forests (Stephenson and Mantgem 2005). A faster individual turnover rate will also contribute to a higher rate of encounter among genotypes in communities, thus contributing to the overall biotic interactions effect.

Data on the seed beetle Stator limbatus (Chrysomelidae, Bruchinae) suggest that the assumption of no cancellation of biotic interactions by shorter lifespan may hold true. First, a study that investigated temperature-dependent selection on male body size for taking off and reaching females (MoyaLaraño et al. 2007) found that temperature mediated the rate at which males and females interacted, with a larger percentage of males being able to reach females at $30^{\circ} \mathrm{C}$ $(28 \% \pm 6)$ than at $20^{\circ} \mathrm{C}\left(7 \% \pm 2\right.$; paired $t$-test, $t_{7}=3.8, P=$ 0.007). Average percentages were calculated across 8 experimental replicates (corresponding to 8 lines of artificial selection for large or small body sizes) from each of which tens of beetles were released at each temperature (thus the paired test). Additional data for the same selection lines (Stillwell et al. unpublished data) show that adult lifespan of mated females is $5.5 \pm 0.0$ days at $34^{\circ} \mathrm{C}$ and $17.6 \pm 0.7$ days at $22^{\circ} \mathrm{C}$. Thus, while the encounter rate with males can be 4 times greater at higher temperatures $(28 / 7)$, the ratio of lifespan at high and low temperatures is only approximately 3 times. Thus, higher temperature alone would still lead to a higher rate of sexual encounters despite shortening the adult lifespan. Provided that, as expected, these beetles are engaged in other types of biotic interactions (e.g. Fox 2000; Stillwell et al. 2007), the rate of interactions at high temperatures must be even higher under natural conditions.

A higher encounter rate among genotypes can potentially lead to more frequent direct interactions, as well as more frequent indirect ecological effects (Wootton 1994). Therefore, the number (and thus the diversity) of interacting genotypes encountered by an individual should be higher in the tropics. But, how can this highly interacting environment lead to the maintenance of greater amounts of genetic diversity?

\section{Hypothesis 3: Biotic Interactions Enhance the Maintenance of Genetic Diversity}

The maintenance of genetic variation in traits under selection is a central question in evolutionary biology and it is not completely clear what factors contribute to it in natural populations (Felsenstein 1976; Hedrick 1986; Bulmer 1989; Curtsinger et al. 1994; Rowe and Houle 1996; Tomkins et al. 2004; Byers 2005). Continuing directional and/or stabilizing selection could erode genetic variation of traits (Fisher 1930), and it is still not well understood how substantial genetic variation for future response to selection is maintained. Balancing or fluctuating selection across space and time (i.e. in heterogeneous environments) may contribute to the maintenance of genetic polymorphisms of individual loci, especially when selection is soft (Dempster 1955; Felsenstein 1976; Hedrick 1976, 1986, 2006, 2007); that is, when selection is density and frequency dependent (Wallace 1975). Furthermore, variable selection in heterogeneous environments can also contribute to the maintenance of genetic variation. For instance, Kassen (2002) documented that in 11 out of 12 cases populations in heterogeneous environments maintained higher genetic variation than in homogeneous environments. For variable selection to maintain genetic diversity of polygenic traits, genotype and environment must interact (GxE) in the sense that the rankorder in the mean fitness of genotypes changes depending on the environment (i.e. the reaction norms for fitness cross among genotypes) (Gillespie and Turelli 1989; MitchellOlds 1992; Zhivotovsky and Gavrilets 1992; Wade 2007). Since the genotypes (and thus the phenotypes) of interacting individuals are part of an individual's environment, for biotic interactions we can say that the rank order of mean fitness of genotypes changes according to the identity of the genotype with which they are interacting (i.e. a GxG interaction in fitness, e.g. Ferrari et al. 2007; Tétard-Jones et al. 2007). Therefore, theoretically, in an environment in which biotic interactions are more important as selective agents than abiotic factors, where soft selection is more frequent, and where each GxG encounter can potentially contribute to an increase in fitness GxE, genetic diversity should be more easily maintained. Indeed, multispecies interactions have been proposed to enhance the maintenance of genetic variation (Strauss and Irwin 2004). Below, I propose a mechanism by which genetic diversity can be maintained from more frequent and diverse biotic interactions.

\section{Concept: Interaction Drift - Biotic Interactions Maintain Fine-Grained Environments that Enhance Genetic Diversity}

A fine-grained environment is an environment that fluctuates substantially over an individual's lifetime (Levins 1968). Abiotic factors such as water availability and temperature have higher seasonal fluctuations at higher latitudes. However, overall these fluctuations will produce an environment of coarser grain (i.e. they fluctuate less often over the lifetime of an individual) when compared to the fluctuations induced from a high rate of meaningful biotic encounters, which should entail an environment of relatively finer grain (i.e. there is a high number of interactions of variable effects during an individual's lifetime). Therefore, the grain of the environment must increase with latitude, with the tropics being fine-grained heterogeneous environments due to the relatively higher rate of biotic interactions allowed by water and temperature.

Fischer (1960) has already hypothesized that the intensity and direction of selection changes from place to place 
depending on the relative contribution of biotic and abiotic factors. Fluctuating selection in fine-grained heterogeneous environments, such as those composed mostly of biotic interactions, should therefore be rather diffuse. This is because each genotype $\mathrm{x}$ genotype encounter is a potential selective agent acting upon a target population and each encounter may differ substantially depending on the identity of the genotypes that encounter each other. These selective agents will have, on average, small population effects (as they will affect at most the two individuals encountering each other) and from one agent to another the direction of selection will change frequently, thus setting the basis for the maintenance of high genetic diversity within populations and species. Interactions with multiple biotic selective agents entail opposite selective pressures within generations (DeWitt and Langerhans 2003; Gómez 2008), supporting the hypothesis that a biotic environment has a fine grain in terms of natural selection. Widespread multiple biotic selective agents acting in opposite directions could be responsible for the fairly small magnitude of directional selection found in nature (Kingsolver et al. 2001). Indeed, the order in which genotypes interact with each other and the associated fitness effects may largely contribute to diffuse coevolution.

I define interaction drift (analogously to genetic and ecological drift) as the random effect that the order and identity of $\mathrm{GxG}$ interactions may have on an individual's fitness. From birth to death, an individual will encounter a number of meaningful genotypes with which it will interact. The rank-abundance curve of genotypes (Fig. 3a) has been considered without regard to which species each genotype belongs to, and a similar-shaped curve for plant genotypes across species can be found in Whitlock et al. (2007). What follows are the results of a simulation (a code written in $\mathrm{R}$ can be obtained from the author upon request), in which I simulated the history of encounters of 50 individuals sharing
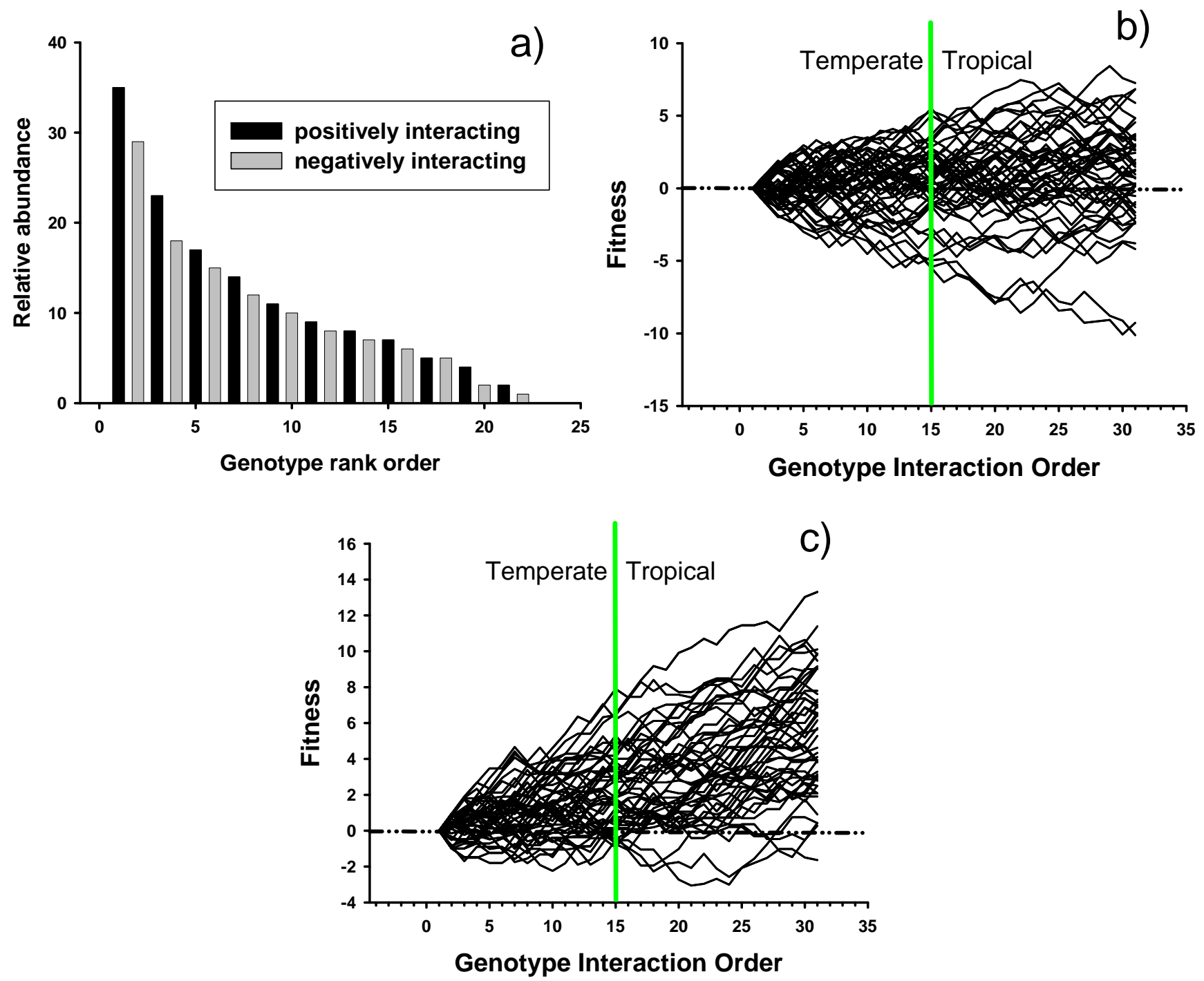

Fig. (3). A simple simulation showing how stronger interaction drift from more frequent biotic interactions can increase GxE in tropical environments and contribute to the maintenance of higher genetic diversity. a) Rank-abundance curve of positively and negatively interacting genotypes. b) The lifetime fitness of 50 individuals with identical genotypes and with identical potential to interact with the same genotypes will drift apart depending on the random subsample of genotypes that they encounter and the order in which they encounter them. c) A similar simulation to b) but with 50 individuals sharing an adaptive genotype, which prevents interactions with those genotypes that have strong negative fitness effects (deviation from mean fitness $<-0.9$ ). 
identical genotypes and which interacted randomly with individuals (and hence genotypes) that followed the rankabundance curve highlighted above. Fig. (3b) shows the lifetime fitness of these 50 individuals. Across individuals, fitness will drift apart depending on the random subsample of genotypes that each individual encounters and also on the order in which these genotypes are encountered. From left to right, each step represents the fitness effect (positive or negative) of an interacting genotype on the target individual during its entire lifetime. Here, for simplicity, the fitness effect of each genotype $\mathrm{x}$ genotype interaction varies from 0 to 1 arbitrary units (positive interactions to the target genotype - successful foraging, mutualism) or from 0 to -1 (negative non-lethal interactions - parasitism, predation threat). All individuals start with the average fitness in the population (reflecting average genotypes), which has been centered to zero (dashed and double dotted horizontal line in Fig. 3b). I only consider those individuals that reproduce successfully, and thus viability selection has been ignored. The green vertical line depicts an arbitrary boundary on the number of interactions between temperate and tropical habitats. The important fact to highlight is that drift is higher because, on average, an individual will interact with more genotypes in the tropics.

Although a large proportion of interactions will not occur in a random order (habitat selection, searching behavior and decision making, for example, bias the order of interactions), it is reasonable to think that some will (but see next section). As interactions occur in sequential order, the order of interactions may cause fitness to drift, as in other examples of random biological drift (Fig. 3b). The important evolutionary effect of interaction drift is that across genotypes within the population it leads to an increase of GxE and thus can potentially contribute to maintain genetic diversity within populations. Since in wet and warm (tropical) environments individuals will interact with more genotypes and thus with a higher diversity of them (Fig. 2), drift will have a stronger effect leading to higher $\mathrm{GxE}$ and thus to the maintenance of higher genetic diversity (Fig. 3b). Supporting the hypothesis that the order in which environments are experienced may affect the patterns of natural selection, an experiment with the butterfly Pieris rapae suggested that the temporal order and duration of environmental conditions affected selection on thermal performance curves (Kingsolver et al. 2007). In addition, when adaptive genotypes are subject to interaction drift, the biotic niche space can be expanded.

\section{Hypothesis 4: Genotype Coexistence - A Higher Rate of Biotic Interactions Increases the Biotic Niche Space}

There is evidence that in the tropics "diversity begets diversity" (e.g. Fischer 1960, MacArthur 1969; Williams 1975; Wills et al. 1997). According to MacArthur (1969), an increase in species richness leads to the establishment of new niche axes, which subsequently allow the accommodation of yet more species in the community. A similar pattern can occur at the genotype level, if more and more diverse biotic interactions increase the biotic niche space allowing the accommodation of more genotypes in the community. This can be better understood if we consider that interaction drift leading to strong GxE - from more frequent and more diverse biotic interactions in wet and warm environments increases the chances for adaptive genotypes to be maintained in communities. Here, the niche space would be expanded because the fitness-enhancing effect of an adaptive trait would be stronger when more encounters occur during an individual's lifetime. Indeed, if we include a deterministic component to the interaction drift simulation above, such as a genotype having evolved adaptive behavior that helps prevent interactions with encountered genotypes that cause a substantial decrease in fitness (-0.9), what we see is an important non-linear effect in which fitness becomes increasingly asymmetrically positive as more encounters occur from left to right (Fig. 3c). This means that there are more opportunities for genotype maintenance in the community. Thus, the more encounters individuals experience, the wider the biotic niche space. Hence, the net effect of mixing adaptive behavior with interaction drift is that average fitness tends to rise with the increasing number of biotic encounters that an individual experiences during its lifetime (Fig. 3c). In other words, more frequent and diverse encounters increase interaction choice. Thus, all other things being equal (e.g. physiological, developmental and physical constraints, resource limitation), the number of opportunities for different genotypes to persist in communities increases substantially when more and more diverse encounters are experienced by each individual; i.e. the biotic niche space has been widened. Assuming that each species in a community counts as a different genotype, this mechanism could also have implications for species coexistence. Thus, an increase in biotic niche space from a higher encounter rate allows more room for specialization, which has been shown to be substantially more important in the tropics (Dyer et al. 2007).

\section{Hypothesis 5: Multidimensionality - Connecting the n- Dimensional Niche to the G-Matrix}

Importantly, a high encounter rate with different genotypes can make the pattern of selection multidimensional, meaning that different selective agents can act simultaneously, and independently, on different traits. In niche theory terms, I hypothesize that fluctuating selection (GxE) would occur in orthogonal niche dimensions (e.g. McPeek 1996; Nosil \& Sandoval 2008), which would be more likely to affect genetically uncorrelated traits, thus contributing to maintain non-correlated genetic variation among different traits. In other words, the fact that selection occurs in orthogonal niche dimensions could promote the accumulation and maintenance of mutations that are not pleoitropic (noncorrelational mutations). Hence, high-latitude environments, where selection from temperature fluctuations dominates, will tend to impose selection in fewer dimensions, just because there will be a lower diversity of biotic selective pressures. In low-latitude environments, where diverse biotic selection occurs, selection on multiple dimensions will tend to be more common. This should be especially true once a population is simultaneously engaged in a relatively high diversity of biotic interactions (e.g. predation, competition, parasitism, mutualism). Thus, the multidimensional niche effect from biotic interactions proposed by MacArthur (1969), which would allow the accommodation of yet more species, can be further expanded to include multidimensional fluctuating selection. Thus, these additional niche axes 
would allow the accommodation of more species/genotypes and enhance the accumulation of non-correlated mutations.

There are several definitions of genetic diversity for both discrete and continuous traits (reviewed in Hughes et al. 2008). I use a definition of genetic diversity that is an approximation based on the infinitesimal model for quantitative traits, in which the breeding values for a trait are determined by the summed effects of many loci, each of which contributes a small part (Schluter 2000). An extension of genetic diversity from discrete traits to quantitative traits can be allelic richness (Hughes et al. 2008), which can be thought of as the average number of alleles in each of the loci that contribute to a quantitative trait. In addition, I use another definition of genetic diversity which relies on the number and magnitude of orthogonal axes in which the genetic variance-covariance matrix of quantitative traits $(\mathbf{G})$ can be decomposed, also called the genetic degrees of freedom (Schluter 2000). All other things being equal, evolution will follow the genetic line of least resistance (Lande 1979), i.e. the direction of the $\mathbf{G}$ axis that absorbs most of the variation in $\mathbf{G}\left(\mathrm{g}_{\max }\right)$. The matrix $\mathbf{G}$ can thus be decomposed into

\section{Temperate}

a)

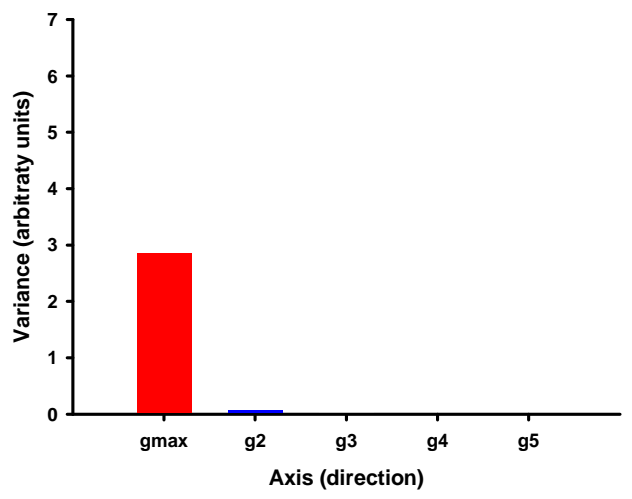

b)

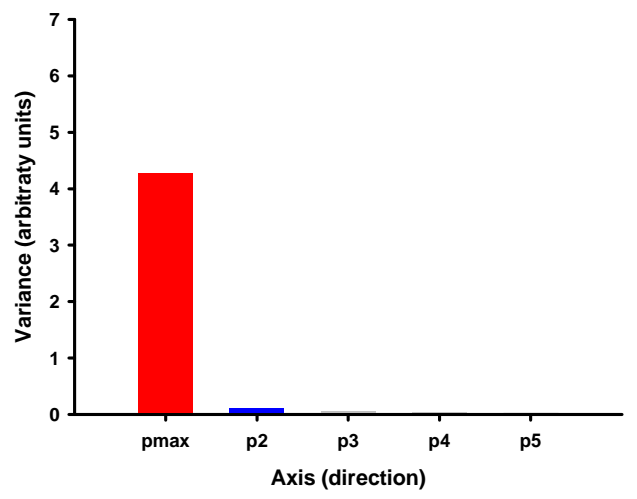

independent axes that can be thought of as the possible directions that evolution can take or as the genetic degrees of freedom. These axes are arranged from the highest to the lowest proportion of variance absorbed (Fig. 4) (See Schluter 2000). Schluter (2000) proposes the adoption of Levin's index of diversity $(L)$ to quantify the evenness in the decomposition of $\mathbf{G}$ into orthogonal axes:

$$
L=1 / \sum p_{i}^{2}
$$

where $p_{i}$ is the proportion of total additive variance accounted for by direction (axis) $i$. If all the variance is in the first direction $\left(\mathrm{g}_{\max }\right), L=1$ and if the variance is equally distributed, $L=m$, where $m$ is the number of traits under consideration. Thus, I hypothesize that when compared to temperate environments, tropical environments should have higher genetic diversity within traits (allele richness), coming from a fine-grained fluctuating environment, and also higher genetic diversity $(L)$ coming from multidimensional fluctuating selection (Fig. 4). Values presented in Fig. (4) are arbitrary. However, the Levins' indices of evenness

\section{Tropical}
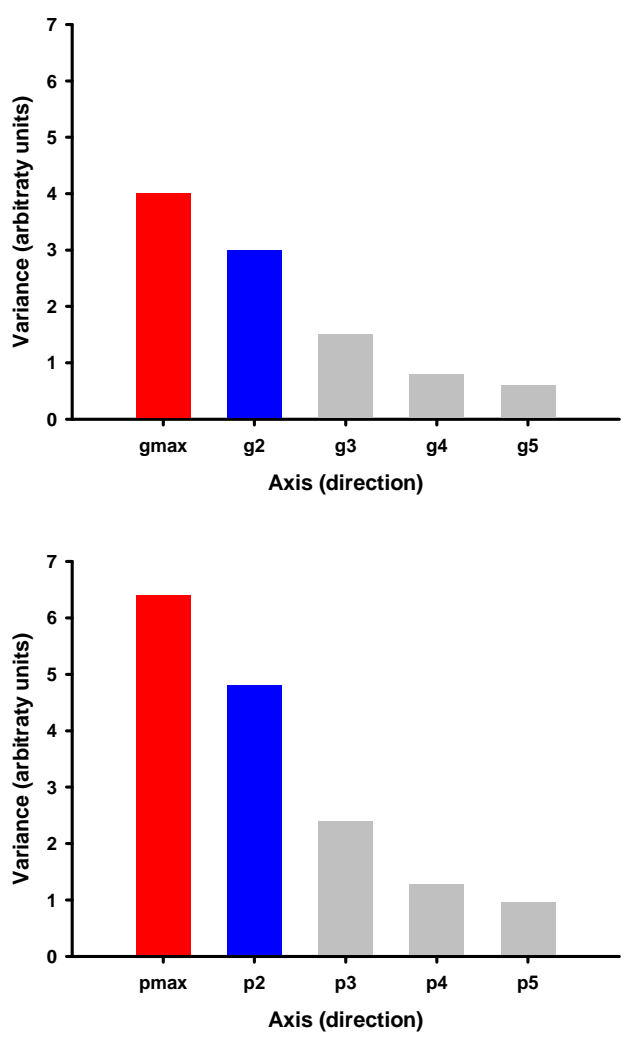

Fig. (4). a) More frequent and more diverse biotic encounters in the tropics can lead to the maintenance of higher multidimensional genetic diversity if more biotic encounters also mean a higher number of dimensions in which selection occurs. The end result may be a higher evenness among the axes in which the genetic variance-covariance matrix (G) can be decomposed (higher multidimensional genetic diversity according to a Levins index of evenness). b) Since a higher diversity of biotic encounters in the tropics entails an environment of finer grain, the evolution of reaction norms for labile traits (e.g. behavior) should be enhanced. As a consequence, in the tropics phenotypic variancecovariance matrices (P) would be more diverse (Levin's index, see text) than $\mathbf{G}$ matrices. 
$\left(L_{\text {temperate }}=1.1, L_{\text {tropics }}=3.5\right)$ lay within the range reported in the literature (Schluter 2000).

Supporting the hypothesis that different types of interactions lead to higher multidimensional genetic diversity, a meta-analysis of genetic correlations between plant resistances to multiple enemies showed that the degree of genetic correlation among resistance traits was higher when both enemies were of the same kind (either pathogens or herbivores), and decreased when the two enemies were of different kind (Leimu \& Koricheva 2006). The stability of the G-matrix over evolutionary time is currently under discussion (e.g. Jones 2003; Revell 2007). In general, fluctuating selection and low or fluctuating correlational selection and mutation (Turelli 1988, Revell 2007) can contribute to destabilizing the G-matrix in terms of direction and the degree of correlation among traits. Certainly, a fine-grained biotic environment with diverse selective pressures and strong interaction drift could lead to unstable G-matrices that would maintain high, uncorrelated genetic variation across orthogonal axes (but see Herrera et al. 2002).

\section{Hypothesis 6: Strong GxE from Biotic Interactions may Lead to Adaptive Flexibility}

Substantial GxE in the tropics from interaction drift could be counteracted by adaptive plasticity (Schlichting and Pigliucci 1998). Indeed, phenotypic flexibility of labile traits is theoretically more likely to evolve in fine-grained environments (Via \& Lande 1985). Thus, at least in labile traits, more biotic encounters in the tropics could also lead to the evolution of wider and more flexible reaction norms. Since a prerequisite for phenotypic plasticity is that organisms should be able to sense the changes in the environment to later change their phenotypes accordingly (Schlichting and Pigliucci 1998), an important prediction is that where biotic interactions are more frequent and diverse, more accurate senses should evolve. Returning to Fig. (2), individuals in the tropics will be selected to accrue as much information as possible about their biotic environment just because they encounter more and more diverse genotypes per unit of time. This alone should set the basis for the adaptive evolution of the senses since a higher diversity of phenotypes needs to be identified. An individual that is able to distinguish most of the phenotypes that it encounters and to respond to them accordingly by phenotypic plasticity, will have higher fitness than an individual unable to distinguish among phenotypes. Thus, the evolution of accurate senses and the evolution of phenotypic flexibility should go hand and hand when biotic encounters are frequent. Animals have been known for a long time to have accurate senses; a fact that is also being acknowledged lately for plants (Karban 2008). Furthermore, the multidimensionality of the biotic environment in the tropics should also be reflected in the evolution of reaction norms, allowing the evolution of independent norms of reaction among traits leading to multidimensional plasticity and high phenotypic diversity (Fig. 4).

The norms of reaction depend on the identity of the species with which interaction occurs (e.g. Relyea 2001; Callaway et al. 2003). Actually, biotic interactions are thought to be at the core of phenotypic plasticity (Agrawal 2001). Among plastic traits, behavior is the most responsive and labile trait in animals (West-Eberhard 2003) and possibly in plants (Karban 2008). A prediction that comes from all of the above is that behavioral plasticity should increase with decreasing latitude. Wider behavioral plasticity should contribute to decrease the effect of the stronger interaction drift in the tropics. Morphological and physiological plasticity, although not as responsive, are also influenced by biotic interactions (Agrawal 2001) and should also co-variate with latitude.

In summary, a biotic, warm, wet, fine-grained and multidimensional environment can potentially facilitate the maintenance of high genetic diversity within populations as well as potentially promote the evolution of flexible and complex reaction norms.

\section{Hypothesis 7: Interactions in the Tropics should be both Stronger and More Diverse}

One of the hypotheses that aims to explain the latitudinal diversity gradient of species richness is the "biotic interactions hypothesis", which is based on the premise that interactions are stronger in abiotically mild tropical environments (see earlier review) (Schemske 2002; Willig et al. 2003; Mittelbach et al. 2007). Since in the tropics abiotic factors of global effect do not constrain the pace of life, populations have more time to interact, which can reasonably lead to stronger interactions among populations (Mittelbach et al. 2007). However, at the genotype level, the strength of interactions among genotypes could decrease when a higher diversity of genotypes is encountered by each individual, as more opportunities to diversify interactions and to dilute the effects of particular interactions occur. A higher encounter rate means finding both more of the same genotype, and a higher diversity of genotypes (Fig. 2), which may even widen the biotic niche (Fig. 3c). Even if we consider each species as a different genotype, this should be true. Whether interactions tend to be stronger or more diverse will depend on the distribution of interacting genotypes. Higher evenness in the distribution of genotypes should lead to more diverse and weaker interactions in the tropics.

Thus, by increasing the encounter rate among genotypes, tropical environments should have both stronger and more diverse interactions. Stronger interactions should lead to higher pair-wise rates of coevolution and cospeciation, while diverse interactions should lead to diffuse coevolution, stronger GxE and the maintenance of more genetic and phenotypic variation. Both processes could work together causing a net acceleration of species diversification in the tropics. Higher levels of specialization in the tropics (e.g. Dyer et al. 2007) could, in turn, be explained, in addition to that from wider niche spaces, by this net effect of accelerated species diversification. Furthermore, more species can be maintained in the tropics because higher genetic and phenotypic diversity can also increase species coexistence (e.g. Vellend and Heber 2005; Peacor et al. 2006; Vellend 2006; Hughes et al. 2008), and can facilitate the establishment of populations in novel habitats by their use of previously unutilized resources (e.g. Jasmin and Kassen 2007).

\section{A FRAMEWORK OF TESTABLE HYPOTHESES}

The theory presented here suggests clear avenues for future research. However, one important task before a 
research programme starts will be to list a set of traits that are more likely subject to biotic than to abiotic selection, or that at least we can be sure are not solely affected by abiotic selection (e.g. animal running speed, foraging efficiency, growth rate, body size, coloration, boldness). Among the possible tests of the theory, the prediction that more diverse genotype $x$ genotype encounters occur as we approach the tropics (hypothesis 1 ) could be tested with field observations quantifying the rate of encounters in target individuals within populations across latitudinal (or altitudinal) gradients. However, to test this hypothesis at the genotype level would require genotyping most individuals of most species in communities, which may be unfeasible. Nevertheless, one possible approximation is considering that each species in the community is a different genotype. Therefore, estimating rank-abundance curves of species and measuring species-tospecies interactions, one can test whether, once having controlled for species richness and abundance, encounters are more frequent and diverse at lower latitudes. Furthermore, the same approach could be used to test the hypothesis that interactions (not just encounters) are stronger and more diverse at lower latitudes (hypothesis 7). In parallel, one could test the assumption that shorter lifespans at lower latitudes do not cancel out more frequent and more diverse biotic interactions.

The manipulation of both temperature and water availability in the laboratory (and hopefully natural) communities can serve to test the hypothesis that higher temperature and water availability leads to a higher rate (and diversity) of genotype $\mathrm{x}$ genotype encounters in a variety of systems (hypothesis 2). Bi-factorial experiments would also help to uncover the separate and joint effects of water and temperature on the rate of genotype encounter. Additionally, by measuring traits subject to biotic selection, some of the above field observations and laboratory experiments might be used to test the hypotheses that selection in these finegrained biotic environments is often fluctuating and multidimensional (hypotheses 3 and 5) and that the biotic niche space is wider (hypothesis 4).

Evidence that the frequency and diversity of $\mathrm{GxG}$ interactions leads to variation in fitness (e.g. Ferrari et al. 2007; Tétard-Jones et al. 2007) across interacting genotypes (analogously to GxE interactions - Byers 2005) could be used to support the hypothesis that the fine-grained nature of biotic interactions can enhance the maintenance of genetic diversity (hypothesis 5). Also, experimentally manipulating the order of interacting genotypes and estimating fitness can serve to demonstrate the potential effect of interaction drift. This should lead to the maintenance of higher amounts of genetic and phenotypic variation. Thus, the general prediction that populations have higher genetic and phenotypic diversity across gradients of water and temperature (and latitude/altitude) should also be tested. Whenever possible, these tests should control for other sources of genetic diversity, such as population size (often mediated by area), geographic origin and phylogenetic relationships. Evidence that genetic diversity decreases with latitude has been found in a few taxa (reviewed and criticized in Evans and Gaston 2005). However, the effective evolutionary time hypothesis, which predicts higher rates of nucleotide substitution with decreasing latitude, also predicts higher genetic diversity at lower latitudes (Rohde 1992; Allen et al. 2002). Neverthe- less, an important difference between the effective evolutionary time hypothesis and the theory presented here, is that the latter is based on natural selection in fine-grained biotic environments. Thus, like the evolutionary time hypothesis, the present theory predicts higher genetic diversity for functional genes (i.e. those subject to selection) in warmer environments. What is new, however, is that unlike the effective evolutionary time hypothesis, this theory also predicts higher genetic diversity for functional genes in wetter terrestrial environments and no relationship between the diversity of neutral genes (those not subject to selection) and temperature or water availability. This theory is extensible to aquatic environments, where these predictions should only work for temperature, as water is not a limiting factor. Indeed, the findings in Atlantic salmon (Dionne et al. 2007) (see the Introduction), which show a positive correlation between the diversity of functional (MHC) genes and temperature, but no relationship between neutral (microsatellite) genes and temperature, are consistent with the predictions of the present theory but not with the effective evolutionary time hypothesis.

Experiments in quantitative genetics (Falconer \& McKey 1996; Roff 1997; Lynch \& Walsh 1998), with populations coming from different locations within water-temperature gradients, could also be used to test the hypothesis that populations coming from warm and wet environments have higher (multidimensional) genetic diversity of traits that are subject to biotic selection (hypothesis 5). Similarly, the hypothesis that there is more flexibility in those labile traits subject to biotic selection (hypothesis 6) in populations that live in warm and wet environments could be tested in common garden experiments. In these experiments one would check if the norms of reaction for traits subject to biotic selection are wider and more flexible in populations coming from warm and wet environments relative to populations coming from cooler and/or drier environments. The prediction would be that, when transferred to environment $\mathrm{B}$, those individuals coming from relatively wet and warm populations that have been reared in environment A, would reach phenotypes closer to those individuals originally reared in environment $\mathrm{B}$. On the other hand, when transferred to environment $\mathrm{B}$, individuals coming from drier or cooler populations reared in environment A, should achieve phenotypes that would be farther away from the typical individuals reared in environment B. Ideally, in order to assign all the observed variation to plasticity, for each population origin, one should use individuals sharing the same genotypes in each environment (A and B). Furthermore, this hypothesis also predicts more accurate senses in wet and warm environments. In some taxa, this prediction could be tested by measuring the sensitivity ranges of the different senses across gradients of temperature and water.

In addition, we would need further modeling to test the effects of interaction drift and its implications for adaptive evolution within networks of interacting genotypes. For instance, individual-based models (DeAngelis and Mooij 2005) within mutualistic and antagonistic networks, including limiting resources, could be implemented to reveal whether more frequent and more diverse interactions truly lead to the maintenance of higher amounts of genetic diversity coming from interaction drift and wider biotic niche spaces. 
Lastly, since the biological activity of ectotherms is more tightly linked to temperature, all the predictions above should apply more closely to ectotherms than to endotherms. Indeed, in birds and mammals, the latitudinal diversity gradient could be explained by a higher extinction rate at higher latitudes rather than by a higher rate of species formation in the tropics (Weir and Schluter 2007).

\section{CONCLUDING REMARKS}

Since the present theory predicts more functional genetic and phenotypic diversity in warm and wet environments and genetic and phenotypic diversity have been linked to both speciation and species coexistence, it can help to explain the latitudinal diversity gradient and other diversity gradients across the globe. For instance, it can explain why deserts are relatively less diverse than other areas of identical latitude where rainfall is greater. Also, altitudinal gradients in diversity can be explained at least partially by this theory.

Lastly, ongoing, human-induced global climate change is making abiotic gradients change at rates that have no precedents in the history of the Earth (Climate Change 2007). While the trend is for an increase of temperature across our planet, rainfall, and thus water availability for terrestrial biota, will increase in some parts of the planet and decrease in others (Climate Change 2007). Thus, this theory also predicts a concomitant change in genetic and phenotypic diversity with climate change that can eventually affect the genetic pool and thus the fate of natural populations.

\section{ACKNOWLEDGEMENTS}

This paper is dedicated to the memory of José Laraño Cano for his lifetime support. I am indebted to J. Hill for her helpful editorial suggestions. I thank C. Armas, J. Bascompte, A. Caballero, D. Cairns, M.A. Calero, J. Carnicer, P.H. Crowley, E. De Mas, C.W. Fox, B.A. Hawkins, J. Hortal, Z. Kikvidze, P. Laiolo, A. LópezLlandrés, A. Martínez-Vázquez, M.A. McPeek, N. Melguizo, M. Méndez, J.M. Montoya, A.G. Nicieza, R.E. Ricklefs, J.J. Soler, A. Torrents, O. Verdeny, D.H. Wise and M. Whitlock for helpful comments on previous drafts of this manuscript. J. Hortal, M. Méndez and R. Ricklefs provided relevant bibliography. Z. Kikvidze suggested expanding the theory to include water availability in addition to temperature. E. De Mas helped organize the large amount of literature originally used during this project. I thank C. Stillwell and C. Fox for kindly letting me use the S. limbatus lifespan data. This work was partially financed by grant CGL2007-60520 and by a Ramón y Cajal research contract from the Spanish Ministry of Science and Innovation, and by grant 020/2008 from the Spanish Ministry for the Environment.

\section{REFERENCES}

Agrawal, AA (2001) Ecology - Phenotypic plasticity in the interactions and evolution of species. Science, 294, 321.

Allee, WC, Emerson, AE, Park, O, Park, T \& Schmidt, KP (1949) Principles of animal ecology, Saunders: Philadelphia.

Allen, AP, Brown, JH \& Gillooly, JF (2002) Global biodiversity, biochemical kinetics, and the energetic-equivalence rule. Science, 297,1545 .
Álvarez, D, Cano, JM, \& Nicieza, AG (2006) Microgeographic variation in metabolic rate and energy storage of brown trout: countergradient selection or thermal sensitivity. Evolutionary Ecology, 20, 345.

Arita, HT, \& Vázquez-Domínguez, E (2008) The tropics: cradle, museum or casino? A dynamic null model for latitudinal gradients of species diversity. Ecology Letters, 11, 653.

Baird, JM, \& May, ML (2003) Fights at the dinner table: Agonistic behavior in Pachydiplax longipennis (Odonata : Libellulidae) at feeding sites. Journal of Insect Behavior, 16, 189-216.

Blanck, A, \& Lamouroux, N (2007) Large-scale intraspecific variation in life-history traits of European freshwater fish. Journal of Biogeography, 34, 862-75.

Bauwens, D, Garland, T, Castilla, AM \& Vandamme, R (1995) Evolution of sprint speed in lacertid lizards - morphological, physiological, and behavioral covariation. Evolution, 49, 848-63.

Bulmer, MG (1989) Maintenance of genetic-variability by mutation selection balance - a childs guide through the jungle. Genome, 31, 761-67.

Byers, DL (2005) Evolution in heterogeneous environments and the potential of maintenance of genetic variation in traits of adaptive significance. Genetica, 123, 107-24.

Callaway, RM, Pennings, SC \& Richards, CL (2003) Phenotypic plasticity and interactions among plants. Ecology, 84, 1115-28.

Cano, JM (2006) Temperature, metabolic rate, and constraints on locomotor performance in ectotherm vertebrates. Functional Ecology, 20, 464-70.

Climate Change (2007) IPCC Fourth Assessment Report.

Cunningham, S \& Read, J (2003) Comparison of temperate and tropical rainforest tree species: growth responses to temperature. Journal of Biogeography, 30, 143-53.

Currie, DJ, Mittelbach, GG, Cornell, HV, Field, R, Guegan, JF, Hawkins, BA, Kaufman, DM, Kerr, JT, Oberdorff, T, O'Brien, E \& Turner, JRG (2004) Predictions and tests of climate-based hypotheses of broad-scale variation in taxonomic richness. Ecology Letters, 7, 1121-34.

Curtsinger, JW, Service, PM, \& Prout, T (1994) Antagonistic pleiotropy, reversal of dominance, and genetic-polymorphism. American Naturalist, 144, 210-28.

DeAngelis, DL \& Mooij, WM (2005) Individual-based modeling of ecological and evolutionary processes. Annual Review of Ecology Evolution and Systematics, 36, 147-68.

Dempster, ER (1955) Maintenance of genetic heterogeneity. Cold Spring Harbor Symposia on Quantitative Biology, 20, 25-32.

Dewitt, TJ \& Langerhans, RB (2003) Multiple prey traits, multiple predators: keys to understanding complex community dynamics. Journal of Sea Research, 49, 143-55.

Dionne, M, Miller, KM, Dodson, JJ, Caron, F \& Bernatchez, L (2007) Clinal variation in mhe diversity with temperature: Evidence for the role of host-pathogen interaction on local adaptation in Atlantic salmon. Evolution, 61, 2154-64.

Dobzhansky, T (1950) Evolution in the tropics. American Scientist, 38, 20921.

Dyer, LA, Singer, MS, Lill, JT, Stireman, JO, Gentry, GL, Marquis, RJ, Ricklefs, RE, Greeney, HF, Wagner, DL, Morais, HC, Diniz, IR, Kursar, TA \& Coley, PD (2007) Host specificity of Lepidoptera in tropical and temperate forests. Nature, 448, 696-99.

Emana, GD (2007) Comparative studies of the influence of relative humidity and temperature on the longevity and fecundity of the parasitoid, Cotesia flavipes. Journal of Insect Science, 7, 19.

Evans, KL. \& Gaston, KJ (2005) Can the evolutionary-rates hypothesis explain species-energy relationships? Functional Ecology, 19, 899915.

Falconer, DS. \& Mackey, TFC (1996) Introduction to quantitative genetics, Longmans, Green, Harlow: Essex.

Felsenstein, J (1976) Theoretical population-genetics of variable selection and migration. Annual Review of Genetics, 10, 253-80.

Ferrari, J, Scarborough, CL \& Godfray, HCJ (2007) Genetic variation in the effect of a facultative symbiont on host-plant use by pea aphids. Oecologia, 153, 323-29.

Fischer, AG (1960) Latitudinal variation in organic diversity. Evolution, 14, 64-81.

Fisher, RA (1930) The genetical theory of natural selection, Chalrendon: Oxford.

Fittkau, EJ \& Klinge, H (1973) On Biomass and Trophic Structure of the Central Amazonian Rain Forest Ecosystem. Biotropica, 5, 2-14. 
Fox, CW (2000) Natural selection on seed-beetle egg size in nature and the laboratory: Variation among environments. Ecology, 81, 3029-35.

Gilbert, GS (2005) Dimensions of plant disease in tropical forests. Biotic interactions in the tropics. Their role in the maintenance of species diversity. In: Burslem, D, Pinard, M \& Hartley, S, (Eds.). Cambridge Univ. Press, Cambridge, pp. 141-64.

Gillespie, JH \& Turelli, M (1989) Genotype-environment interactions and the maintenance of polygenic variation. Genetics, 121-38.

Gómez, JM (2008) Sequential conflicting selection due to multispecific interactions triggers evolutionary trade-offs in a monocarpic herb. Evolution, 62, 668-79.

Guernier, V, Hochberg, ME \& Guegan, JFO (2004) Ecology drives the worldwide distribution of human diseases. Plos Biology, 2, 740-46.

Hautekeete, NC, Piquot, Y and Van Dijk, H (2002) Life span in Beta vulgaris ssp maritima: the effects of age at first reproduction and disturbance. Journal of Ecology, 90, 508-16.

Hawkins, BA, Albuquerque, FS, Araujo, MB, Beck, J, Bini, LM, CabreroSanudo, FJ, Castro-Parga, I, Diniz, JAF, Ferrer-Castan, D, Field, R, Gomez, JF, Hortal, J, Kerr, JT, Kitching, IJ, Leon-Cortes, JL, Lobo, JM., Montoya, D, Moreno, JC, Olalla-Tarraga, MA, Pausas, JG, Qian, H, Rahbek, C, Rodriguez, MA, Sanders, NJ \& Williams, $\mathrm{P}$ (2007) A global evaluation of metabolic theory as an explanation for terrestrial species richness gradients. Ecology, 88, 1877-88.

Hawkins, BA, Field, R, Cornell, HV, Currie, DJ, Guegan, JF, Kaufman, DM, Kerr, JT, Mittelbach, GG, Oberdorff, T, O'Brien, EM, Porter, EE \& Turner, JRG (2003) Energy, water, and broad-scale geographic patterns of species richness. Ecology, 84, 3105-17.

Hedrick, PW (1986) Genetic-polymorphism in heterogeneous environments - a decade later. Annual Review of Ecology and Systematics, 17, $535-66$.

Hedrick, PW (2006) Genetic polymorphism in heterogeneous environments: The age of genomics. Annual Review of Ecology Evolution and Systematics, 37, 67-93.

Hedrick, PW (2007) Balancing selection. Current Biology, 17, R230-R231.

Hedrick, PW, Ginevan, ME \& Ewing, EP (1976) Genetic-polymorphism in heterogeneous environments. Annual Review of Ecology and Systematics, 7, 1-32.

Heibo, E, Magnhagen, C and Vollestad, LA (2005) Latitudinal variation in life-history traits in Eurasian perch. Ecology, 86, 3377-86.

Herrera, CM (1995) Microclimate and individual variation in pollinators Flowering plants are more than their flowers. Ecology, 76, 151624.

Herrera, CM, Medrano, M, Rey, PJ, Sánchez-Lafuente, AM, García, MB, Guitián, J \& Manzaneda, AJ (2002) Interaction of pollinators and herbivores on plant fitness suggests a pathway for correlated evolution of mutualism- and antagonism-related traits. Proceedings of the National Academy of Sciences of the United States of America, 99, 16823-28.

Hillebrand, $H$ (2004) On the generality of the latitudinal diversity gradient. American Naturalist, 163, 192-211.

Hughes, AR, Inouye, BD, Johnson, MTJ, Underwood, N \& Vellend, M (2008) Ecological consequences of genetic diversity. Ecology Letters, 11, 609-23.

Ives, AR \& Gilchrist, GW (1993) Climate change and ecological interactions. Biotic interactions and global change. In: Kareiva, PM, Kingsolver, JG \& Huey, RB, (Eds.). Sinauer Associates, Sunderland: MA, USA.

Jacob, TA (1996) The effect of constant temperature and humidity on the development, longevity and productivity of Ahasverus advena (Watl.) (Coleoptera: Silvanidae). Journal of Stored Products Research, 32, 115-21.

Jasmin, JN \& Kassen, R (2007) Evolution of a single niche specialist in variable environments. Proceedings of the Royal Society BBiological Sciences, 274, 2761-67.

Jones, AG, Arnold, SJ, \& Borger, R (2003) Stability of the G-matrix in a population experiencing pleiotropic mutation, stabilizing selection, and genetic drift. Evolution, 57, 1747-60.

Karban, R (2008) Plant behaviour and communication. Ecology Letters, 11, 727-39.

Kassen, R (2002) The experimental evolution of specialists, generalists, and the maintenance of diversity. Journal of Evolutionary Biology, 15, $173-90$.

Keilin, D (1959) The leeuwenhoek lecture - the problem of anabiosis or latent life - history and current concept. Proceedings of the Royal Society of London Series B-Biological Sciences, 150, 149-91.
Kingsolver, JG, Hoekstra, HE, Hoekstra, JM, Berrigan, D, Vignieri, SN, Hill, CE, Hoang, A, Gibert, P \& Beerli, P (2001) The strength of phenotypic selection in natural populations. American Naturalist, $157,245-61$.

Kingsolver, JG, Massie, KR, Shlichta, JG, Smith, MH, Ragland, GJ \& Gomulkiewicz, R (2007) Relating environmental variation to selection on reaction norms: An experimental test. American Naturalist, 169, 163-74.

Kope, HH, Alfaro, RI, \& Lavallee, R (2008) Effects of temperature and water activity on Lecanicillium spp. Conidia germination and growth, and mycosis of Pissodes strobi. Biocontrol, 53, 489-500.

Kozlowski, TT \& Pallardy, SG (2002) Acclimation and adaptive responses of woody plants to environmental stresses. Botanical Review, 68, 270-334.

Kruse, PD, Toft, S, \& Sunderland, KD (2008) Temperature and prey capture: opposite relationships in two predator taxa. Ecological Entomology, 33, 305-12.

Lande, R (1979) Quantitative genetic-analysis of multivariate evolution, applied to brain - body size allometry. Evolution, 33, 402-16.

Latimer, AM (2007) Geography and resource limitation complicate metabolism-based predictions of species richness. Ecology, 88, 1895-98.

Leimu, R, \& Koricheva, J (2006) A meta-analysis of genetic correlations between plant resistances to multiple enemies. American Naturalist, 168, E15-E37.

Levins, R (1968) Evolution in changing environments, Princeton Univ. Press: Princeton

Lynch, M, \& Walsh, B (1998) Genetics and analysis of quantitative traits. Sinauer Associates, Sunderland.

Macarthur, RH (1969) Patterns of communities in the tropics. Biological Journal of the Linnean Society, 1, 19-30.

Mcpeek, MA (1996) Linking local species interactions to rates of speciation in communities. Ecology, 77, 1355-66.

Merino, S, Moreno, J, Vasquez, RA, Martinez, J, Sanchez-Monsalvez, I, Estades, CF, Ippi, S, Sabat, P, Rozzi, R, \& McGehee, S (2008) Haematozoa in forest birds from southern Chile: Latitudinal gradients in prevalence and parasite lineage richness. Austral Ecology, 33, 329-40.

Mitchell-Olds, T (1992) Does environmental variation maintain geneticvariation - a question of scale. Trends in Ecology \& Evolution, 7, 397-98.

Mittelbach, GG, Schemske, DW, Cornell, HV, Allen, AP, Brown, JM, Bush, MB, Harrison, SP, Hurlbert, AH, Knowlton, N, Lessios, HA, mccain, C. M., mccune, AR, mcdade, LA, mcpeek, MA, Near, TJ, Price, TD, Ricklefs, RE, Roy, K, Sax, DF, Schluter, D, Sobel, JM, \& Turelli, M (2007) Evolution and the latitudinal diversity gradient: speciation, extinction and biogeography. Ecology Letters, $10,315-31$.

Mittelbach, GG, Steiner, CF, Scheiner, SM, Gross, KL, Reynolds, HL, Waide, RB, Willig, MR, Dodson, SI \& Gough, L (2001) What is the observed relationship between species richness and productivity? Ecology, 82, 2381-96.

Moya-Laraño, J, El-Sayyid, MET \& Fox, CW (2007) Smaller beetles are better scramble competitors at cooler temperatures. Biology Letters, 3, 475-478.

Nosil, P, \& Sandoval, CP (2008) Ecological niche dimensionality and the evolutionary diversification of stick insects. PloS ONE, 3, e1907.

Peacor, SD, Riolo, RL, \& Pascual, M (2004) Phenotypic plasticity and species coexistence: Modeling food webs as complex adaptive systems. Workshop on From Structure to Dynamics in Complex Ecological Networks. In: Pascual, M \& Dunne, JA (Eds.). Santa Fe: NM, pp. 245-70.

Relyea, RA (2001) Morphological and behavioral plasticity of larval anurans in response to different predators. Ecology, 82, 523-40.

Revell, LJ (2007) The G matrix under fluctuating correlational mutation and selection. Evolution, 61, 1857-72.

Ricklefs, RE (2004) A comprehensive framework for global patterns in biodiversity. Ecology Letters, 7, 1-15.

Ricklefs, RE, \& Schluter, D (1993) Species diversity: regional and historical influences. In Species diversity in ecological communities In: Ricklefs, R. E. and Schluter, D. (Eds.). Univ. Of Chicago Press: Chicago, pp. 350-63.

Rinde, E,\& Sjotun, K (2005) Demographic variation in the kelp Laminaria hyperborea along a latitudinal gradient. Marine Biology, 146, 105162. 
Roff, DA (1997) Evolutionary quantitative genetics, Chapman and Hall: New York.

Rohde, K (1992) Latitudinal gradients in species-diversity - the search for the primary cause. Oikos, $65,514-27$.

Rosenzweig, ML (1995) Species diversity in space and time, Cambridge Univ. Press: Cambridge.

Rowe, L, \& Houle, D (1996) The lek paradox and the capture of genetic variance by condition dependent traits. Proceedings of the Royal Society of London Series B-Biological Sciences, 263, 1415-21.

Salkeld, DJ, Trivedi, M, \& Schwarzkopf, L (2008) Parasite loads are higher in the tropics: temperate to tropical variation in a single hostparasite system. Ecography, 31, 538-44.

Schemske, DW (2002) Ecological and evolutionary perspectives on the origins of tropical diversity. Foundations of tropical forest ecology: classic papers with commentaries. In: Chazdon, RL, and Whitmore, TC, (Eds.). Univ. of Chicago Press: Chicago, pp. 163-73.

Schlichting, CD, \& Pigliucci, M (1998) Phenotypic evolution: a reaction norm perspective, Sinauer associates, Sunderland: MA, USA.

Schluter, D (2000) The ecology of adaptive radiation, Oxford Univ. Press: Oxford.

Schmidt, PS, Matzkin, L, Ippolito, M, \& Eanes, WF (2005) Geographic variation in diapause incidence, life-history traits, and climatic adaptation in Drosophila melanogaster. Evolution, 59, 1721-32.

Speakman, JR (2005) Body size, energy metabolism and lifespan. Journal of Experimental Biology, 208, 1717-30.

Stephenson, NL \& Van Mantgem, PJ (2005) Forest turnover rates follow global and regional patterns of productivity. Ecology Letters, 8, 524-31.

Stillwell, RC, Morse, GE, \& Fox, CW (2007) Geographic variation in body size and sexual size dimorphism of a seed-feeding beetle. American Naturalist, 170, 358-69.

Strauss, SY, \& Irwin, RE (2004) Ecological and evolutionary consequences of multispecies plant-animal interactions. Annual Review of Ecology Evolution and Systematics, 35, 435-66.

Tétard-Jones, C, Kertesz, MA, Gallois, P, \& Preziosi, RF (2007) Genotypeby-genotype interactions modified by a third species in a plantinsect system. American Naturalist, 170, 492-99.

Tomkins, JL, Radwan, J, Kotiaho, JS, \& Tregenza, T (2004) Genic capture and resolving the lek paradox. Trends in Ecology \& Evolution, 19, 323-28.

Tsunoda, T (2008) Influence of aggregation and relative humidity on longevity of unfed bush tick, Haemaphysalis longicornis neumann (Acari : Ixodidae). Journal of Parasitology, 94, 990-92.
Turelli, M (1988) Phenotypic evolution, constant covariances, and the maintenance of additive variance. Evolution, 42, 1342-47.

Vellend, M (2006) The consequences of genetic diversity in competitive communities. Ecology, 87, 304-11.

Vellend, M, \& Geber, MA (2005) Connections between species diversity and genetic diversity. Ecology Letters, 8, 767-81.

Via, S, \& Lande, R (1985) Genotype-environment interaction and the evolution of phenotypic plasticity. Evolution, 39, 505-22.

Wade, MJ (2007) The co-evolutionary genetics of ecological communities. Nature Reviews Genetics, 8, 185-95.

Wallace, AR (1878) Tropical nature and other essays, Macmillan: London $\&$ New York.

Wallace, B (1975) Hard and soft selection revisited. Evolution, 29, 465-73.

Walter, H (1975) Climate-diagram maps of the individual continents and the ecological climatic regions of the earth, Springer-Verlag: Berlin.

Weir, JT, \& Schluter, D (2007) The latitudinal gradient in recent speciation and extinction rates of birds and mammals. Science, 315, 1574-76.

Went, FW (1949) Ecology of desert plants. 2. The effect of rain and temperature on germination and growth. Ecology, 30, 1-13.

West-Eberhard, MJ (2003) Developmental plasticity and evolution, Oxford Univ. Press: Oxford.

Wheeler, QD (1990) Insect diversity and cladistic constraints. Annals of the Entomological Society of America, 83, 1031-47.

Williams, GC (1975) Sex and evolution, Princeton Univ. Press: Princeton.

Willig, MR, Kaufman, DM, \& Stevens, RD (2003) Latitudinal gradients of biodiversity: Pattern, process, scale, and synthesis. Annual Review of Ecology Evolution and Systematics, 34, 273-309.

Wills, C, Condit, R, Foster, RB, \& Hubbell, SP (1997) Strong density- and diversity-related effects help to maintain tree species diversity in a neotropical forest. Proceedings of the National Academy of Sciences of the United States of America, 94, 1252-57.

Wootton, JT (1994) The nature and consequences of indirect effects in ecological communities. Annual Review of Ecology and Systematics, 25, 443-66.

Zhivotovsky, LA, \& Gavrilets, S (1992) Quantitative variability and multilocus polymorphism under epistatic selection. Theoretical Population Biology, 42, 254-83.

Ziuganov, V, San Miguel, E, Neves, RJ, Longa, A, Fernandez, C, Amaro, R, Beletsky, V, Popkovitch, E, Kaliuzhin, S, \& Johnson, T (2000) Life span variation of the freshwater pearl shell: A model species for testing longevity mechanisms in animals. Ambio, 29, 102-5.

Received: August 14, 2009

Revised: September 03, 2009

Accepted: October 22, 2009

(C) Jordi Moya-Laraño; Licensee Bentham Open.

This is an open access article licensed under the terms of the Creative Commons Attribution Non-Commercial License (http://creativecommons.org/licenses/by$\mathrm{nc} / 3.0 /$ ), which permits unrestricted, non-commercial use, distribution \& reproduction in any medium, provided the work is properly cited. 